\title{
Comparison of bronchodilator responses and deposition patterns of salbutamol inhaled from a pressurised metered dose inhaler, as a dry powder, and as a nebulised solution
}

\author{
B M Z Zainudin, M Biddiscombe, S E J Tolfree, M Short, S G Spiro
}

\begin{abstract}
The lung dose and deposition patterns of drug delivered by dry powder inhaler are not known. The effects of inhaling $400 \mu \mathrm{g}$ salbutamol delivered by dry powder inhaler (two $200 \mu \mathrm{g}$ salbutamol Rotacaps), by pressurised metered dose inhaler, and by Acorn nebuliser were studied in nine subjects with chronic stable asthma. Technetium-99m labelled Teflon particles were mixed with micronised salbutamol in the pressurised metered dose inhaler and in the capsules; technetium-99m labelled human serum albumin was mixed with the salbutamol solution for the nebuliser study. The pressurised metered dose inhaler deposited $11.2 \%$ (SEM $0.8 \%$ ) of the dose within the lungs; this was significantly more than the dose deposited by the dry powder inhaler $(9 \cdot 1 \%(0.6 \%))$, but did not differ significantly from the dose delivered by the nebuliser $(9.9 \%$ $(0.7 \%))$. Distribution within the peripheral third of the lung was significantly greater with the nebuliser than with the other two systems; $\mathrm{FEV}_{1}$ improved to a significantly greater extent after inhalation of $400 \mu \mathrm{g}$ salbutamol from the pressurised metered dose inhaler $(35.6 \%$ from baseline) than from the nebuliser $(25 \cdot 8 \%)$ or dry powder inhaler $(25 \cdot 2 \%)$. Thus after inhalation of similar doses of salbutamol a larger proportion of drug was deposited within the lungs when it was inhaled from a metered dose inhaler than from a dry powder system; the nebuliser achieved the greatest peripheral deposition. The bronchodilator response seems to depend on the amount of drug within the lungs rather than its pattern of distribution.
\end{abstract}

Department of Respiratory Medicine B M Z Zainudin $S$ E J Tolfree $S$ G Spiro

Department of Medical Physics, University College Hospital, London $M$ Biddiscombe M Short

Address for reprint requests: Dr S G Spiro, Brompton Hospital, London SW3 6HP. Accepted 20 February 1990 ively. ${ }^{4}$ For children a dry powder inhaler may delivery .system. ${ }^{5}$ Although dry powder inhalers have been used for the management of asthma for more than a decade, very little is known about the pattern of drug delivery within the body or the amount that is deposited in the lungs.

In an assessment in vitro salbutamol delivery from a dry powder inhaler (Rotacap) appeared to be half as efficient as delivery from the pressurised metered dose inhaler ${ }^{6}$; as a result the dose recommended for patients is twice that of the dose used with the pressurised inhaler. Clinical studies, however, have provided less clearcut conclusions, some showing equipotency for the two forms of delivery ${ }^{67}$ and others suggesting a better response with the pressurised inhaler system. ${ }^{89}$ Because of these controversies and the lack of data on deposition patterns of dry powder medication within the respiratory tract, we have compared the deposition pattern of salbutamol administered by dry powder inhaler, from a pressurised metered dose inhaler, and an Acorn nebuliser.

\section{Methods}

SUBJECTS

We studied nine subjects with chronic stable asthma (three men, six women) aged 20-68 years. They had a history of well documented asthma of 10-60 years' duration and showed an improvement in $\mathrm{FEV}_{1}$ of more than $15 \%$ from baseline after $200 \mu \mathrm{g}$ of salbutamol delivered by pressurised metered dose inhaler. Their mean baseline $\mathrm{FEV}_{1}$ was $55 \%$ (SD $20^{\circ}{ }_{0}$ ) of the predicted values according to age, sex, and height. ${ }^{10}$ All were regularly inhaling corticosteroids and bronchodilators, and three were also taking oral theophylline preparations. Their inhaler techniques were assessed before the study and were found to be satisfactory. They were studied on three occasions at least three days apart to ensure complete decay of the radioactivity. Oral bronchodilators were discontinued 18 hours and inhaled bronchodilators 12 hours before the study but inhaled corticosteroids were continued as usual.

The study was approved by the ethical committee of University College and Middlesex School of Medicine. powder bronchodilator aerosol more effectalso be more effective than a pressurised
STUDY DESIGN

The aim of the study was to compare the deposition patterns and change in lung function after similar doses of salbutamol given from a pressurised cannister, a dry powder 
inhaler, and an Acorn nebuliser.

The subjects inhaled in random order the following doses of salbutamol mixed with the radionuclide technetium- $99 \mathrm{~m}$ :

$1400 \mu \mathrm{g}$ salbutamol (Ventolin) delivered from a pressurised metered dose inhaler (four puffs, $100 \mu \mathrm{g}$ a puff), the actuation being made at the beginning of a slow, deep inhalation followed by a 10 second breath hold;

$2400 \mu \mathrm{g}$ salbutamol delivered as a dry powder (two $200 \mu \mathrm{g}$ salbutamol (Ventolin) Rotacaps) via a Rotahaler, each capsule being inhaled twice rapidly, with a 10 second breath hold on each occasion;

$3400 \mu \mathrm{g}$ salbutamol, nebulised with an Acorn jet nebuliser for the nebuliser study, inhaled through a mouthpiece at tidal volume until the nebuliser was dry.

For each subject the deposition pattern was assessed by gamma camera imaging of the lungs, throat, and abdomen; lung function was assessed by measuring peak expiratory flow (PEF), $F E V_{1}$, and forced vital capacity (FVC). Readings were made $-30,-15,0,30$, 45 , and 60 minutes from the time of inhalation and the best of three readings recorded on each occasion.

\section{RADIONUCLIDE LABELLING TECHNIQUE}

For the pressurised metered dose and dry powder inhalers technetium-99m labelled Teflon (fluorinated ethylene propylene) particles were manufactured by a May spinning disc generator ${ }^{1112}$ and mixed with micronised salbutamol particles in a reconstituted pressurised metered dose inhaler or in capsules as follows. Firstly, ${ }^{99 \mathrm{~m}} \mathrm{Tc}$ pertechnetate in $10 \mathrm{ml}$ normal saline was passed through a cation exchange column (Amberlite 20) and the eluate collected in a glass container, subsequently evaporated by heating and blowing air across it simultaneously. Next, $0.5 \mathrm{ml}$ of submicron Teflon suspension in $50 \mathrm{ml}$ of $40 \%$ ethanol was added to the technetium residue and the solution was run on to the spinning disc revolving at $62000 \mathrm{rev} / \mathrm{min}$. A 240 watt light bulb served as a heat source within the generator tank to enhance evaporation of liquid droplets and to prevent particle agglomeration..$^{13}$ The particles generated were collected by scraping the glass collection plates placed on the base of the tank and transferring the powder into an empty cannister. This was subsequently heated to $240^{\circ} \mathrm{C}$ to improve the durability of the particles. For the metered dose inhaler preparation $10 \mathrm{GBq}$ of ${ }^{99 \mathrm{~m}} \mathrm{Tc}$ pertechnetate was initially used to label the Tefion particles with $200-400 \mathrm{MBq}$ radioactivity. An activity of $2 \mathrm{GBq}$ was used in the preparation of the dry powder capsules.

For the reconstitution of the pressurised metered dose inhaler the cannister containing the technetium labelled particles was cooled to $-60^{\circ} \mathrm{C}$ by immersion in solid carbon dioxide. A commercial 80 dose cannister containing micronised salbutamol, chlorofluorocarbon propellants, and surfactant was also cooled down to well below the boiling point of the propellant mixture. The top of the commer- cial cannister was then quickly removed by a special blade and the contents were transferred into the cannister containing the Teflon particles. A new metering valve was quickly secured in position and crimped to the cannister. The process of transferring the contents and securing the valve was completed in less than 10 seconds to prevent the evaporation of the propellants. The reconstituted cannister was then shaken in an ultrasonic bath for 10 minutes to disperse the particles uniformly. Each actuation released $100 \mu \mathrm{g}$ salbutamol with $2 \cdot 0-4 \cdot 0 \mathrm{MBq}$ of radioactivity.

For the reconstitution of dry powder capsules the ${ }^{99 \mathrm{~m}} \mathrm{Tc}$ labelled Teflon particles were weighed accurately with an electronic microbalance (Sartorius $1201 \mathrm{MP2}$ ) and mixed with premixed micronised salbutamol sulphate in lactose powder of a known weight (in the proportion of $200 \mu \mathrm{g}$ salbutamol in every $25 \mathrm{mg}$ of powder mixture). The powder mixture was ground thoroughly with a pestle and mortar and passed through a metal sieve several times. The correct proportion of powder mixture was subsequently weighed and transferred into gelatin capsules. Four or five capsules were usually prepared on each occasion; each contained $200 \mu \mathrm{g}$ salbutamol, $24.8 \mathrm{mg}$ lactose and about $1 \mathrm{mg}$ of technetium-99m labelled Teflon particles with 8$10 \mathrm{MBq}$ of radioactivity. The capsules were then ready for clinical use or performance assessment (quality assurance).

For the nebulised aerosol study $400 \mu \mathrm{g}$ salbutamol solution (Ventolin) was mixed with $100 \mathrm{MBq}{ }^{99 \mathrm{~m}} \mathrm{Tc}$ human serum albumin and normal saline was added to make this up to $4 \mathrm{ml}$. The solution was nebulised to dryness by an Acorn jet nebuliser at 8 litres a minute. The particles produced were inhaled by tidal breathing at a controlled respiratory rate of 18-20 breaths a minute for four minutes. The rate was guided by a metronome and the inspiratory volume by needle deflection on a flow integrator (Gould-Godart).

\section{PARTICLE SIZE ANALYSIS}

Aluminium foil placed on the base of the generator tank was used to collect the Teflon particles settling from the spinning disc for size analysis with a scanning electron microscope. The particles collected by scraping the glass collection plates were examined in the same way. The size of salbutamol particles from the pressurised metered dose inhaler and nebuliser were analysed separately with a Malvern laser diffractometer.

\section{PERFORMANCE ASSESSMENT OF THE} RECONSTITUTED METERED DOSE INHALER AND DRY POWDER CAPSULES

The contents of the reconstituted metered dose inhaler cannister were examined by discharging 10 puffs into a Twin Impinger (Glaxo Limited). The Twin Impinger was operated at an air flow of $60 \mathrm{l} / \mathrm{min}$ so that the two chamber instrument had a 50\% effective cut off diameter of $6.4 \mu \mathrm{m}$, particles of this aerodynamic size having a $50 \%$ probability of 
penetrating to the lower chamber and particles of smaller size having a higher probability of penetration. Methanol was used in both stages as the solvent for collection of salbutamol and Teflon particles. Particles deposited on the actuator and valve and in stages 1 and 2 were assessed for radioactivity with a gamma camera and by assaying for salbutamol spectrophotometrically after the radioactivity had completely decayed.

The reconstituted dry powder capsule containing a mixture of ${ }^{99 \mathrm{~m}}$ Tc labelled Teflon and salbutamol sulphate particles in lactose was also assessed with the Twin Impinger. Distilled water was used as the solvent for collection of salbutamol and Teflon particles. After the capsule had been broken into two halves the powder was sucked through the Twin Impinger with an air flow of $60 \mathrm{l} / \mathrm{min}$ for five seconds. Both the radioactivity and the drug assay of the contents of the Rotahaler, the remaining capsule, and the powder in stages 1 and 2 were assessed by the techniques used for the pressurised metered dose inhaler.

\section{RADIONUCLIDE IMAGING TECHNIQUE}

Immediately after inhaling the radiolabelled aerosol subjects had the imaging performed, seated in front of a dual headed gamma camera (Siemens Rota Camera), which can acquire simultaneous anterior and posterior images. Images of the lungs with or without views of the throat or stomach were collected for a count limit of $300 \mathrm{~K}$ and those including the throat or stomach were collected for a time limit of 120 seconds. The camera was interfaced to an ADAC computer and the data were stored on magnetic tape for subsequent analysis. Radioactivity retained in tubing, nebuliser, actuator valve, Rotahaler, and capsule were all assessed for a time limit of 100 seconds. Counts in the regions of interest delineating the lungs, throat, and stomach were obtained and expressed as percentages of the initial activity in the nebuliser or capsules and, for the pressurised metered dose inhaler, as percentages of the total activity released. These values were corrected for background activity, attenuation of photons (in the throat, chest, or abdominal walls) and radioactive decay. The lungs were divided into a peripheral third and central two thirds.

Baseline lung function values and percentage total and peripheral lung deposition of radioaerosol with improvement in lung function values (mean (SEM))

\begin{tabular}{|c|c|c|c|}
\hline & $\begin{array}{l}\text { Metered dose } \\
\text { inhaler }\end{array}$ & $\begin{array}{l}\text { Dry powder } \\
\text { inhaler }\end{array}$ & Nebuliser \\
\hline $\begin{array}{l}\text { Baseline PEF }(1 / \mathrm{min}) \\
\text { FEV }_{1}(1) \\
\text { FVC (l) }\end{array}$ & $\begin{array}{l}246(25) \\
1 \cdot 40(0 \cdot 13) \\
2 \cdot 25(0 \cdot 19)\end{array}$ & $\begin{array}{l}248(27) \\
1 \cdot 42(0 \cdot 13) \\
2 \cdot 28(0 \cdot 18)\end{array}$ & $\begin{array}{l}246(28) \\
1 \cdot 43(0 \cdot 15) \\
2 \cdot 19(0 \cdot 18)\end{array}$ \\
\hline Radioaerosol deposition & & & \\
\hline $\begin{array}{l}\text { Total lung }\left({ }^{\circ}\right) \\
\text { Peripheral lung }\left({ }^{\circ} \% \text { of total }\right) \\
\text { Improvement }\left(\left(_{0}^{\circ}\right) \text { o }\right.\end{array}$ & $\begin{array}{l}11 \cdot 2(0 \cdot 8) \\
16 \cdot 1(1.2)\end{array}$ & $\begin{array}{r}9 \cdot 1(0 \cdot 6) \\
12 \cdot 7(1 \cdot 3)\end{array}$ & $\begin{array}{r}9.9(0.7) \\
24.5(1.0)\end{array}$ \\
\hline $\begin{array}{l}\text { PEF } \\
\text { FEV } \\
\text { FVC }\end{array}$ & $\begin{array}{l}40 \cdot 1(6 \cdot 6) \\
35 \cdot 6(7 \cdot 4) \\
25 \cdot 4(4 \cdot 4)\end{array}$ & $\begin{array}{l}32 \cdot 4(6 \cdot 7) \\
25 \cdot 2(6 \cdot 2) \\
19 \cdot 7(5 \cdot 3)\end{array}$ & $\begin{array}{l}29.9(5 \cdot 2) \\
25 \cdot 8(6.5) \\
24 \cdot 4(6.0)\end{array}$ \\
\hline
\end{tabular}

PEF-peak expiratory flow; $\mathrm{FEV}_{1}$-forced expiratory volume in one second; FVC—forced vital capacity.

\section{STATISTICAL ANALYSIS}

Analysis of variance was used to identify differences in baseline values of lung function, total and peripheral deposition of aerosol, and changes in lung function in the three treatment groups. Multiple comparisons between groups were performed by means of a linear contrast method. A p value of $<0.05$ was taken as significant. For the analysis of change in PEF, $\mathrm{FEV}_{1}$, and FVC changes at 30, 45, and 60 minutes were added together and the mean values used for the comparison.

\section{Results}

VALIDATION

The mass median diameter (MMD) of Teflon particles was 2.1 (SD 1.5) $\mu \mathrm{m}$ and that of salbutamol was $1.45(1.4) \mu \mathrm{m}$. The mass median diameter of nebulised ${ }^{99 \mathrm{~m}} \mathrm{Tc}$ human serum and salbutamol particles was $2 \cdot 3$ (2.4) $\mu \mathrm{m}$.

The results of the Twin Impinger study with the pressurised metered dose inhaler showed a mean (SD) percentage radioactivity of 10.2 (3.0), $52.6(6.0)$, and $37 \cdot 1(6.8)$ in the actuator, stage 1 , and stage 2 . The corresponding mean (SD) percentages of salbutamol were $9.7(2.5)$, $45.0(4 \cdot 3)$, and $44 \cdot 7(4 \cdot 7)$. The differences between the radioactivity and the drug were small and considered acceptable. For the dry powder the mean (SD) percentage radioactivity values were $29.5(4 \cdot 2), 59 \cdot 0(2 \cdot 1)$, and $11.5(3.4)$ in the Rotahaler, stage 1 , and stage 2 , compared with $23.5(2 \cdot 1), 62.0(1.4)$, and $14.5(0.7)$ for the drug. In total, 13 runs were performed with a metered dose inhaler and four with a dry powder inhaler.

\section{IN VIVo STUDY}

Mean baseline values of PEF, $\mathrm{FEV}_{1}$, and FVC for the three studies were similar (table). The percentage of total deposition and the percentage of the total that entered the peripheral third of the lung in each subject are shown in figure 1. The greatest total lung deposition was achieved after inhalation from the pressurised metered dose inhaler, with a mean (SEM) of $11 \cdot 2{ }_{\circ}(0.8 \%)$ of the released dose (table). This was significantly greater than the deposition achieved with the dry powder $(9 \cdot 1 \%(0.6 \%)$, $\mathrm{p}<0.025)$, but not the acorn nebuliser $(9.9 \%$ $\left(0.7^{\circ}\right)$. The mean percentage peripheral lung deposition of aerosol was significantly greater with the nebuliser than the pressurised metered dose inhaler $(p<0.001)$, and the metered dose inhaler was in turn significantly better than the dry powder $(p<0.05)$. The improvement in $\mathrm{FEV}_{1}$ was significantly greater with the pressurised metered dose inhaler than either the dry powder or the nebuliser $(\mathrm{p}<0.025)$. There was no significant difference in $\mathrm{FEV}_{1}$ between the dry powder and the nebuliser.

The improvement in PEF showed a trend towards a greater response with the metered dose inhaler similar to that of $\mathrm{FEV}_{1}$, but the differences between the three methods did not reach statistical significance. The increase in FVC was similar after the three forms of aerosol inhalation. 


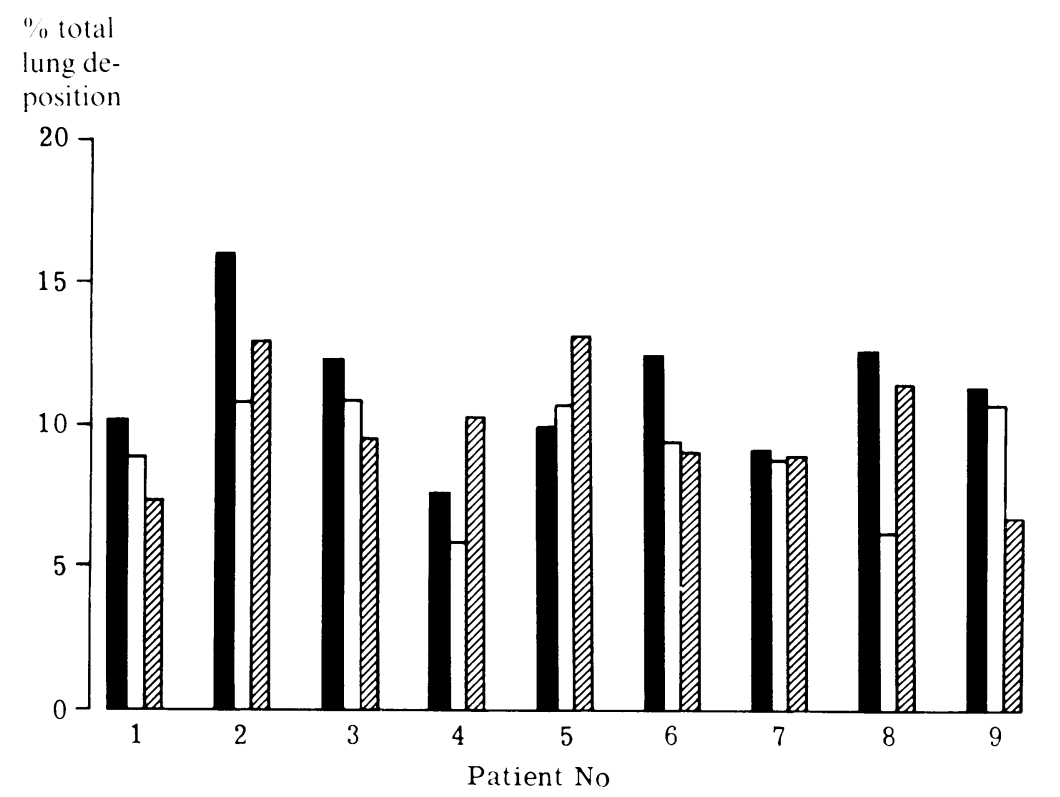

a)

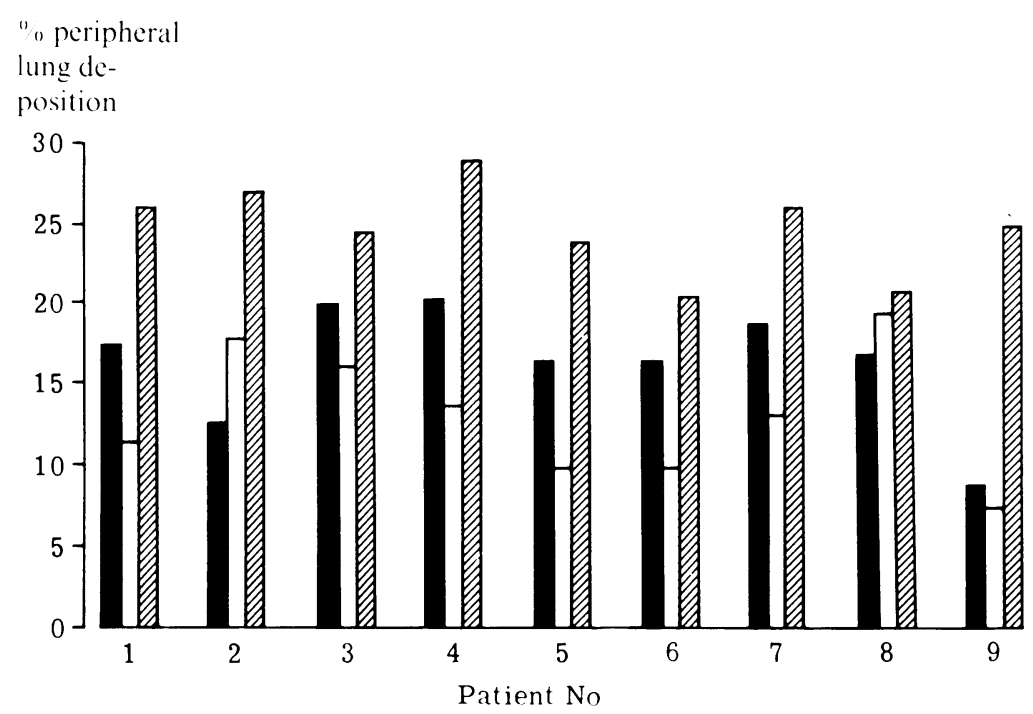

(b)

Figure 1 Percentage deposition of radioaerosol in each study in (a) the total lung and (b) the peripheral third of the lung. $\mathbf{\square}$ Metered dose inhaler; II DPI-dry powder inhaler; $\mathbb{Z}$ nebuliser.

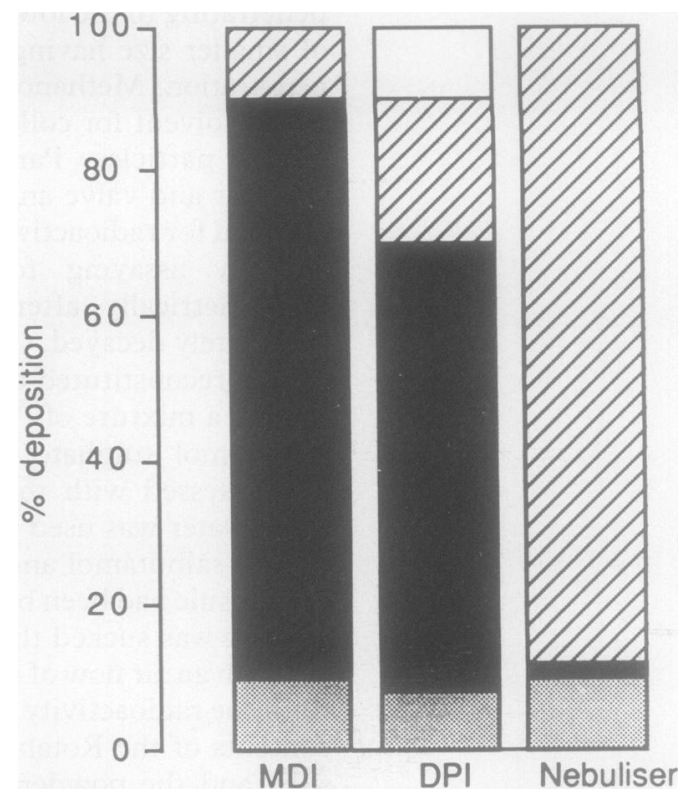

Figure 2 Percentage deposition of aerosol delivered by the metered dose inhaler ( $M D I)$, the dry powder inhaler (DPI), and the nebuliser at different sites.

gastrointestinal tract; $\mathbb{Z}$ apparatus; $\mathbf{\square}$ loss to the air.

pressurised metered dose inhaler. The use of Teflon particles that are not totally matched to the size distribution of the drug particles may not be ideal, but the differences in size were small and unlikely to have caused important differences in the pattern of deposition. This is certainly true for the pressurised metered dose inhaler, as shown previously. ${ }^{14}$ Direct labelling of salbutamol would be ideal for these studies but the technique is not available. Our Twin Impinger data, however, suggest very similar deposition of the drug and Teflon particles. Our results with the pressurised metered dose inhaler are close to previous estimates of doses deposited in the lung. ${ }^{15-18}$

Bronchodilator responses seem to be related more to the total dose of bronchodilator deposited within the lungs than to the pattern of distribution. The response was greatest with the pressurised metered dose inhaler than either the dry powder or the Acorn nebuliser, despite the fact that the nebuliser deposited more drug in the peripheral third of the lung than the other two techniques. Although the total lung dose achieved by the pressurised metered dose inhaler and nebuliser did not differ significantly, the bronchodilator response was greater with the former; this perhaps suggests some contribution from the drug deposited in the oropharynx to bronchodilatation, as noted in previous studies. ${ }^{1920}$

We have compared the deposition patterns and bronchodilator responses of three commonly used delivery systems for salbutamol. After starting with an identical drug dose the pressurised metered dose inhaler deposits a significantly greater dose within the lungs than the dry powder system and achieves a significantly greater increase in lung function. Nevertheless earlier estimates suggesting that the latter delivers only half as efficiently as the 
metered dose inhaler considerably underestimate the dry powder system.

We wish to express our appreciation to the Glaxo Group Research Ltd, Ware, Hertfordshire, for providing the material and some technical assistance; the School of Pharmacy, University of London, for providing the scanning electron microscopic and Malvern Particle Sizer analyses; the Pharmacy Department, University College Hospital, for allowing us to use the ultraviolet spectrophotometer; and Miss Angela Betchley for typing the manuscript. B M Z Z was supported by the University Kebangsaan, Malaysia.

1 Epstein SW, Manning CPR, Ashley MJ, Corey PN. Survey of the clinical use of pressurised aerosol inhalers. Can Med Ass $J 1979 ; 120: 813-6$.

2 Crompton GK. Problems patients have using pressurised aerosol inhalers. Eur J Respir Dis 1982;63(suppl 119): 101-4

3 Orehek J, Gayrard P, Grimaud CH, Charpin J. Patient error in use of bronchodilator metered aerosols. $\mathrm{Br} \mathrm{Med}$ 1976;i:76.

4 Paterson IC, Crompton GK. Use of pressurised aerosols by asthmatic patients. $\mathrm{Br}$ Med J 1976; i:76-7.

5 Chambers S, Dunbar J, Taylor B. Inhaled powder compared with aerosol administration of fenoterol in asthmatic with aerosol administration of fen

6 Svedmyr N, Lofdahl C, Svedmyr K. The effect of powder aerosol compared to pressurised aerosol. Eur J Respir Dis 1982;63: (suppl 119):81-8.

7 Hetzel MR, Clark TJH. Comparison of Salbutamol rotahaler with conventional pressurised aerosol. Clin Allergy 1977;7:563-8.

8 Duncan D, Paterson IC, Harris D, Crompton GK. Comparison of the bronchodilator effects of salbutamo inhaled as a dry powder and by conventional pressurised aerosol. Br J Clin Pharmacol 1977;4:669-71.

9 Hartley JPR, Nogrady SG, Seaton A. Longterm comparison of salbutamol powder with salbutamol aerosol in asthmatic out-patients. Br J Dis Chest 1979;73:271-6.

10 Cotes JE. Lung function: principles and application in medicine. 3rd ed. Oxford: Blackwell, 1975:380-9.

11 Camner $P$, Philipson K. Production of Monidisperse fluorocarbon resin particles tagged with $18 \mathrm{~F}$. Int J Appl Radiat Isotopes 1971;22:349-53.

12 Newman SP, Pavia D, Moren F, Sheahan NF, Clarke SW. Deposition of pressurised aerosols in the human respiratory tract. Thorax $1981 ; 36: 52-5$.

13 Hurford MJ. Production of ferric oxide aerosols with a May Spinning-top aerosol generator, J Aerosol Sci 1981; 12:441-56.

14 Newman SP, Killip M, Pavia D, Moren F, Clarke SW. The effect of changes in particle size on the deposition of pressurised inhalation aerosols. Int J Pharmacol 1984;19:333-7.

15 Davies DS. Pharmacokinetics of inhaled substances. Postgrad Med J 1975;51(suppl 7):69-75.

16 Newman SP, Pavia D, Garland N, Clarke SW. Effects of various inhalation modes on the deposition of radioactive pressurised aerosols. Eur J Respir Dis 1982;63(suppl 119):57-65.

17 Spiro SG, Singh CA, Tolfree SEJ, Partridge MR, Short MD. Direct labelling of ipratropium bromide aerosol and its deposition pattern in normal subjects and patients with chronic bronchitis. Thorax 1984;39:432-5.

18 Vidgren MT, Karkkainen A, Karjalainen P, Paronen TP. A novel labelling method for measuring the deposition of drug particles in the respiratory tract. Int J Pharmacol drug particles in

19 Rodenstein D, Stanescu DC. Mouth spraying versus inhalation of fenoterol aerosol in healthy subjects and asthmatic patients. Br J Dis Chest 1982;76:365-73.

20 Shore SC, Weinberg EG, Durr MH. Buccal administration of fenoterol aerosol in young children with asthma. $S$ Afr Med J 1976;50:1362-4. 